\title{
Predictors of Exercise-Induced Oxygen Desaturation in Systemic Sclerosis Patients With Interstitial Lung Disease
}

\author{
Fujiko Someya MD, Naoki Mugii OTR, Minoru Hasegawa MD, \\ Tetsutarou Yahata MD, and Takao Nakagawa MD
}

\begin{abstract}
BACKGROUND: The diffusion capacity of the lung for carbon monoxide $\left(\mathrm{D}_{\mathrm{LCO}}\right)$ is a good marker of disease severity in patients with idiopathic interstitial pneumonia, and is associated with oxygen saturation; however, little is known about $D_{\mathrm{LCO}}$ in systemic sclerosis patients with interstitial lung disease. We studied potential predictors of exercise-induced oxygen desaturation in patients with systemic sclerosis. METHODS: Data were collected prospectively from 80 of 110 consecutive systemic sclerosis patients with normal oxygen saturation $(>95 \%)$ at rest, who could perform the 6-min walk test without physical discomfort, including leg pain. Pulmonary function tests and echocardiography were collected from all subjects. RESULTS: Thirty subjects showed a $\geq 4 \%$ decline in oxygen saturation during the 6-min walk test (desaturation group). The other subjects were assigned to the normoxic group. The percent-of-predicted values for $\mathrm{FVC}, \mathrm{FEV}_{1}$, total lung capacity, $D_{L C O}$, and $D_{L C O}$ /alveolar volume were lower, and $\mathrm{FEV}_{1} / \mathrm{FVC}$ was higher, in the desaturation group. Logistic regression analysis showed the percent-of-predicted $D_{L C O}$ as a highly accurate predictor of exercise-induced oxygen desaturation: the area under the receiver operating characteristic curve was 0.92 (cutoff point $56.3 \%$, sensitivity 0.83 , specificity 0.86 ). Five subjects over the cutoff point of the percent-of-predicted $D_{\mathrm{LCO}}$ in the desaturation group could not be distinguished from the normoxic subjects with the lung-volume measurements or right-ventricular systolic pressure. CONCLUSIONS: The factor underlying exercise-induced oxygen desaturation appeared to be reduced percent-of-predicted $D_{\mathrm{LCO}}$, which was useful as a predictor in over $80 \%$ of the subjects. Key words: systemic sclerosis; interstitial lung disease; oxygen saturation; pulmonary function; pulmonary arterial hypertension; 6-min walk test. [Respir Care 2014;59(1):75-80. (c) 2014 Daedalus Enterprises]
\end{abstract}

\section{Introduction}

Exercise-induced oxygen desaturation in patients with interstitial lung disease may be one of the crucial factors in

\footnotetext{
Dr Someya and Dr Nakagawa are affiliated with the School of Health Sciences, Kanazawa University; and Dr Hasegawa is affiliated with the Department of Dermatology, Kanazawa University, Kanazawa, Japan. Mr Mugii is affiliated with the Division of Rehabilitation; and Dr Yahata is affiliated with the Division of Rehabilitation, Kanazawa University Hospital, Kanazawa, Japan.
}

The authors have disclosed no conflict of interest.

Correspondence: Fujiko Someya MD, School of Health Sciences, Kanazawa University, Kodatsuno 5-11-80, Kanazawa 920-0942, Japan. E-mail: fujiko@mhs.mp.kanazawa-u.ac.jp.

DOI: $10.4187 /$ respcare. 02452 exercise limitation. An $\mathrm{S}_{\mathrm{pO}_{2}}$ decrease to $\leq 88 \%$ during the 6-min walk test (6MWT) predicts high mortality risk in patients with idiopathic interstitial pneumonia. ${ }^{1}$ Oxygen desaturation during 6MWT correlates with the diffusion capacity of the lung for carbon monoxide $\left(\mathrm{D}_{\mathrm{LCO}}\right)^{2,3} \mathrm{Im}$ paired $\mathrm{D}_{\mathrm{LCO}}$ and pulmonary arterial hypertension are also found in patients with systemic sclerosis, ${ }^{4,5}$ and low $\mathrm{D}_{\mathrm{LCO}}$ $(\leq 50 \%)$ was one of the predictors of death. ${ }^{6}$ However, $\mathrm{S}_{\mathrm{pO}_{2}}$ decrease of $\geq 4 \%$ during $6 \mathrm{MWT}$ correlates with age, dyspnea index, positive anti-Scl-70 autoantibody, and FVC, but $\mathrm{D}_{\mathrm{LCO}}$ has not been examined in relation to oxygen saturation in patients with systemic sclerosis. ${ }^{7}$

Identifying predictors of exercise-induced oxygen desaturation would help to select patients who might benefit from additional monitoring using oximetry during 6MWT when oxygen saturation is normal at rest. Moreover, the suggestion of cutoff points for these predictors would help 
alert patients to avoid hypoxic risk. ${ }^{8}$ In the present study we used 6MWT as a submaximal exercise to prospectively identify predictors of exercise-induced oxygen desaturation in patients with systemic sclerosis and interstitial lung disease.

\section{Methods}

The study was approved by the ethics committee of Kanazawa University Hospital, Kanazawa, Japan, and all subjects gave written informed consent. Between 2008 and 2012, 110 consecutive adult patients with systemic sclerosis and interstitial lung disease were referred to the Division of Rehabilitation Medicine, Kanazawa University Hospital. Interstitial lung disease was diagnosed via pulmonary function tests, high-resolution computed tomography, and/or open lung biopsy. The main reasons for the patients' visits were for the evaluation and rehabilitation treatment of digit ulcers, joint contracture, and exercise intolerance.

$6 \mathrm{MWT}$ was conducted if $\mathrm{S}_{\mathrm{pO}_{2}}$ was $>95 \%$ at rest on room air. The exclusion criteria were pain in or ulcers on the foot, severe cough, heart failure, or back pain. We enrolled 80 subjects ( 66 female, 14 male), with a mean age of 57.4 years (Fig. 1). During the $6 \mathrm{MWT}_{\mathrm{pO}_{2}}$ was monitored with a handheld pulse oximeter, with a reflectance sensor on the forehead, and was also measured at rest and at the end of the walk, without interfering with the 6MWT.

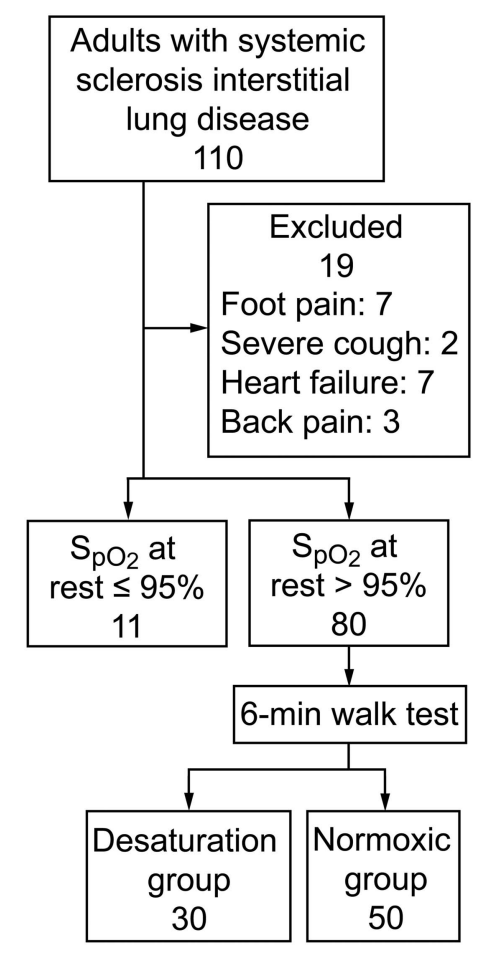

Fig. 1. Flow chart.

\section{QUICK LOOK}

\section{Current knowledge}

The diffusion capacity of the lung for carbon monoxide $\left(D_{\mathrm{LCO}}\right)$ is a good marker of disease severity in patients with idiopathic interstitial pneumonia, and is directly associated with a diminished oxygen saturation. The role of $\mathrm{D}_{\mathrm{LCO}}$ in characterizing interstitial lung disease in patients with systemic sclerosis is not known.

\section{What this paper contributes to our knowledge}

Reduced $\mathrm{D}_{\mathrm{LCO}}$ and percent-of-predicted lung volumes affected oxygen saturation during the 6-min walk test in patients with systemic sclerosis and interstitial lung disease. Percent-of-predicted $\mathrm{D}_{\mathrm{LCO}}$ was a sensitive and specific predictor of exercise-induced oxygen desaturation.

We did not use a fingertip oximetry sensor because digit circulation is often deteriorated in patients with systemic sclerosis, which makes fingertip $\mathrm{S}_{\mathrm{pO}_{2}}$ readings inaccurate. ${ }^{9}$

We measured percent-of-predicted $\mathrm{FVC}, \mathrm{FEV}_{1}, \mathrm{FEV}_{1} /$ FVC, total lung capacity (TLC), peak expiratory flow (PEF), residual volume/TLC (RV/TLC), $\mathrm{D}_{\mathrm{LCO}}$, and $\mathrm{D}_{\mathrm{LCO}} /$ alveolar volume $\left(\mathrm{D}_{\mathrm{LCO}} / \mathrm{V}_{\mathrm{A}}\right)($ Chestac-9800, Chest Medical Instruments, Tokyo, Japan). Each predicted value was calculated with sex, age, and height ${ }^{10}$ (per the Baldwin formula). Single-breath $\mathrm{D}_{\mathrm{LCO}}$ was adjusted by hemoglobin concentration, according to the Cotes equation. ${ }^{2}$

Transthoracic echocardiography (iE33, Philips Healthcare, Best, Netherlands) was performed with the subject in the left-lateral decubitus position. Left-ventricular enddiastolic and end-systolic diameters were determined with M-mode echocardiography, and left-ventricular ejection fraction was calculated with the modified Simpson formula. Right-ventricular systolic pressure (RVSP), reflecting systolic pulmonary artery pressure, was estimated from the tricuspid regurgitating velocity, following the Bernoulli principle, via tissue Doppler echocardiography. ${ }^{11,12}$

\section{Statistics}

Subjects whose $\mathrm{S}_{\mathrm{pO}_{2}}$ decreased $\geq 4 \%$ during 6MWT were assigned to the desaturation group, because exercise desaturation of $\geq 4 \%$ predicts mortality $^{1}$ and is an adverse prognostic sign ${ }^{13}$ in patients with idiopathic pulmonary fibrosis. The remaining subjects constituted the normoxic group. Differences between the 2 groups were calculated with the 2-tailed $t$ test. The chi-square test was used to compare sex distribution and skin-involvement subsets (diffuse versus limited type). Logistic regression was used 
Table. Subjects

\begin{tabular}{|c|c|c|c|c|}
\hline & $\begin{array}{l}\text { All Subjects } \\
\quad n=80\end{array}$ & $\begin{array}{l}\text { Normoxic } \\
\text { Subjects } \\
n=50\end{array}$ & $\begin{array}{c}\text { Desaturation } \\
\text { Subjects } \\
n=30\end{array}$ & $P$ \\
\hline Female/male, no. & $66 / 14$ & $43 / 7$ & $23 / 7$ & .29 \\
\hline Age, y & $57.4 \pm 11.8$ & $57.6 \pm 12.3$ & $57.0 \pm 11.0$ & .80 \\
\hline Duration of disease, $y$ & $6.6 \pm 7.9$ & $6.4 \pm 8.5$ & $7.0 \pm 7.0$ & .73 \\
\hline Skin involvement subset, no. & & & & .055 \\
\hline Diffuse & 45 & 24 & 21 & \\
\hline Limited & 35 & 26 & 9 & \\
\hline FVC, $\%$ predicted & $94.0 \pm 22.9$ & $103.3 \pm 21.4$ & $78.5 \pm 18.3$ & $<.001$ \\
\hline $\mathrm{FEV}_{1}, \%$ predicted & $93.9 \pm 24.0$ & $101.2 \pm 22.4$ & $81.8 \pm 21.8$ & $<.001$ \\
\hline $\mathrm{FEV}_{1} / \mathrm{FVC}$ & $79.9 \pm 8.2$ & $78.3 \pm 8.5$ & $82.5 \pm 7.0$ & .02 \\
\hline PEF, \% predicted & $87.5 \pm 16.5$ & $88.2 \pm 18.4$ & $86.3 \pm 15.6$ & 61 \\
\hline TLC, $\%$ predicted & $85.9 \pm 20.4$ & $95.1 \pm 16.3$ & $70.5 \pm 17.1$ & $<.001$ \\
\hline RV/TLC, \% & $95.5 \pm 15.7$ & $97.1 \pm 14.7$ & $92.9 \pm 17.3$ & .28 \\
\hline $\mathrm{D}_{\mathrm{LCO}}, \mathrm{mL} / \mathrm{min} / \mathrm{mm} \mathrm{Hg}$ & $13.8 \pm 4.5$ & $16.0 \pm 3.7$ & $10.3 \pm 3.2$ & $<.001$ \\
\hline $\mathrm{D}_{\mathrm{LCO}}, \%$ predicted & $62.6 \pm 19.5$ & $72.7 \pm 15.7$ & $45.8 \pm 12.4$ & $<.001$ \\
\hline $\mathrm{D}_{\mathrm{LCO}} / \mathrm{V}_{\mathrm{A}}, \mathrm{mL} / \mathrm{min} / \mathrm{mm} \mathrm{Hg} / \mathrm{L}$ & $4.44 \pm 1.13$ & $4.68 \pm 0.98$ & $4.06 \pm 1.28$ & .03 \\
\hline $\mathrm{D}_{\mathrm{LCO}} / \mathrm{V}_{\mathrm{A}}, \%$ predicted & $84.9 \pm 19.9$ & $89.9 \pm 17.6$ & $76.2 \pm 21.1$ & .005 \\
\hline LVEF, \% & $72.1 \pm 4.7$ & $72.4 \pm 5.2$ & $71.6 \pm 3.9$ & .43 \\
\hline RVSP, mm Hg & $31.1 \pm 9.8$ & $29.8 \pm 8.2$ & $33.2 \pm 11.9$ & .18 \\
\hline 6MWD, m & $492 \pm 102$ & $504 \pm 93$ & $472 \pm 115$ & .21 \\
\hline $\begin{array}{l}\text { Values are means } \pm \text { SD unless otherwise in } \\
\text { PEF = peak expiratory flow } \\
\text { TLC = total lung capacity } \\
\text { RV = residual volume } \\
D_{\text {LCO }} \text { diffusion capacity of the lung for } \\
\mathrm{V}_{\mathrm{A}}=\text { alveolar volume } \\
\text { LVEF = left-ventricular ejection fraction } \\
\text { RVSP = right-ventricular systolic pressure } \\
6 \mathrm{MWD}=6 \text {-min walk distance }\end{array}$ & & & & \\
\hline
\end{tabular}

for parameters regarding exercise-induced oxygen desaturation; then, for parameters with high accuracy (indicated by the area under the receiver operating characteristic curve), sensitivity and specificity were obtained from critical points on the receiver operating characteristic curve. Moreover, all subjects were divided by degree of impairment in percent-of-predicted $\mathrm{D}_{\mathrm{LCO}}$, and lung volumes and RVSP were compared between the $2 \mathrm{D}_{\mathrm{LCO}}$ groups with the 2-tailed $t$ test. Statistical analyses were performed with statistics software (JMP8.0, SAS Institute, Cary, North Carolina), except for the 95\% CI for the area under the receiver operating characteristic curve, which was calculated with SPSS 17.0 (SPSS, Chicago, Illinois). In all analyses, $P<.05$ was taken to indicate significance.

\section{Results}

The Table describes the subjects. There were no differences in sex distribution, age, skin-involvement subset, duration of disease after the onset of Raynaud phenomenon, percent-of-predicted RV/TLC, percent-of-predicted
PEF, left-ventricular ejection fraction, RVSP, or 6MWT distance between the desaturation and normoxic groups. The desaturation group had significantly lower percent-ofpredicted FVC, FEV 1 , TLC, $\mathrm{D}_{\mathrm{LCO}}$, percent-of-predicted $\mathrm{D}_{\mathrm{LCO}}, \mathrm{D}_{\mathrm{LCO}} / \mathrm{V}_{\mathrm{A}}$, and percent-of-predicted $\mathrm{D}_{\mathrm{LCO}} / \mathrm{V}_{\mathrm{A}}$, and significantly higher $\mathrm{FEV}_{1} / \mathrm{FVC}$.

In the logistic regression analysis, percent-of-predicted $\mathrm{D}_{\mathrm{LCO}}$ was the most accurate predictor: area under the receiver operating characteristic curve 0.92 (Fig. 2). At the critical point on the receiver operating characteristic curve, the percent-of-predicted $\mathrm{D}_{\text {LCO }}$ was $56.3 \%$ (sensitivity 0.83 , specificity 0.86). When the cutoff point for percent-ofpredicted $\mathrm{D}_{\mathrm{LCO}}$ was set at $56.3 \%$ for exercise-induced oxygen desaturation, 5 subjects in the desaturation group had percent-of-predicted $\mathrm{D}_{\mathrm{LCO}}>56.3 \%$, defined as the false negative subjects.

All subjects were classified per the percent-of-predicted $\mathrm{D}_{\mathrm{LCO}}$ cutoff point, and then the percent-of-predicted FVC, $\mathrm{FEV}_{1}$, TLC, and RVSP values of the 2 groups were compared (Fig. 3). The percent-of-predicted FVC, $\mathrm{FEV}_{1}$, and TLC values in the desaturation group over the cutoff 


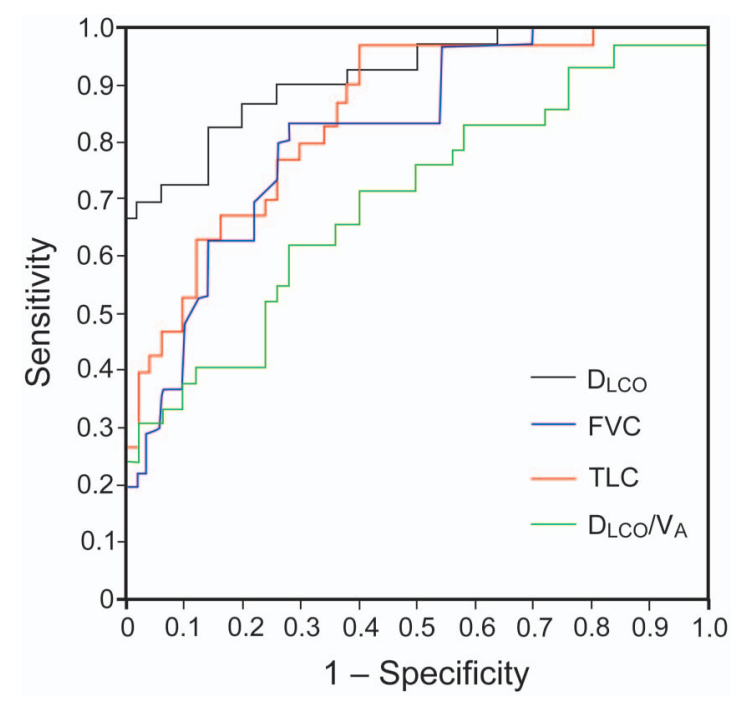

Fig. 2. Receiver operating characteristic curves for parameters affecting oxygen saturation during 6-min walk test. $\mathrm{D}_{\mathrm{LCO}}=$ diffusion capacity of the lung for carbon monoxide. TLC = total lung capacity. $\mathrm{V}_{\mathrm{A}}=$ alveolar volume. The area under the receiver operating characteristic curves were $0.92(95 \% \mathrm{Cl} 0.85-$ 0.98) for percent-of-predicted $D_{\text {LCO }}, 0.82$ (95\% Cl 0.73-0.91) for percent-of-predicted FVC, 0.84 (95\% Cl 0.76-0.93) for percentof-predicted TLC, and $0.70(0.57-0.82)$ for percent-of-predicted $\mathrm{D}_{\text {LCO }} / \mathrm{N}_{\mathrm{A}}$.

point were significantly lower than those in the normoxic group. There was no significant difference in RVSP between the 2 groups. However, 5 false negative subjects showed low values for 3 lung volume parameters, and the range of values of false negative subjects overlapped with that of subjects in the normoxic group. Therefore, it was difficult to predictively distinguish them from subjects in the normoxic group using lung volume parameters, even after classification for percent-of-predicted $\mathrm{D}_{\mathrm{LCO}}$ impairment.

\section{Discussion}

Significantly impaired $\mathrm{D}_{\mathrm{LCO}}, \mathrm{FVC}, \mathrm{FEV}_{1}$, and TLC were found in the desaturation group. Little information has been obtained on the correlation between lung parameters and exercise-induced oxygen desaturation in systemic sclerosis, though FVC previously showed a significant association with induced oxygen desaturation during 6MWT. ${ }^{7}$ Percent-of-predicted $\mathrm{D}_{\mathrm{LCO}}$ has been reported to be a predictor of 6MWT distance in patients with systemic sclerosis and interstitial lung disease. ${ }^{4}$ Exercise-induced oxygen desaturation in patients with idiopathic interstitial pneumonia correlates with walk velocity, percent-of-predicted $\mathrm{D}_{\mathrm{LCO}}$ and arterial oxygen pressure, ${ }^{14}$ percent-of-predicted $\mathrm{D}_{\mathrm{LCO}}$ and pulmonary capillary blood volume, ${ }^{3}$ and $\mathrm{D}_{\mathrm{LCO}} \cdot{ }^{2}$ In support of those studies,
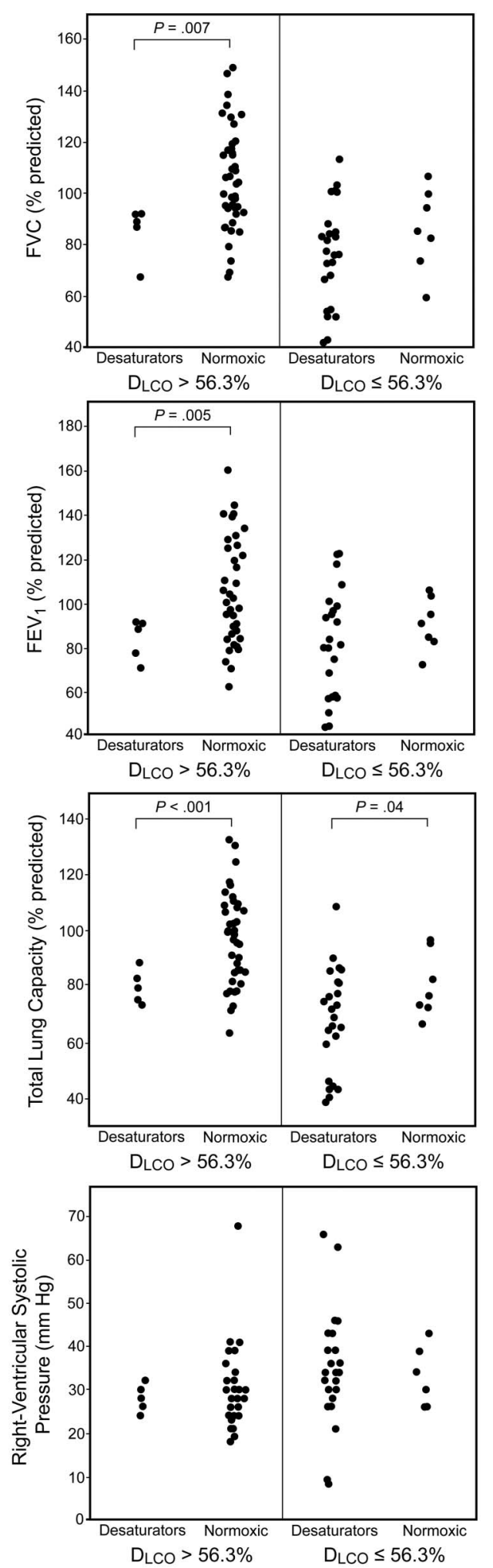

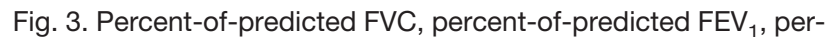
cent-of-predicted total lung capacity (TLC), and right-ventricular systolic pressure in 80 subjects classified according to degree of impairment in diffusion capacity of the lung for carbon monoxide $\left(\mathrm{D}_{\mathrm{LCO}}\right)$, and according to desaturation $\left(\mathrm{S}_{\mathrm{pO}_{2}}\right.$ decrease of $\left.\geq 4 \%\right)$ or normoxia during the 6-min walk test. 


\section{Predictors of Exercise-Induced Oxygen Desaturation in Systemic Sclerosis}

associations have been suggested between lung volume parameters and $\mathrm{D}_{\mathrm{LCO}}$ with exercise-induced oxygen desaturation in patients with systemic sclerosis and interstitial lung disease.

Impaired lung volumes, especially TLC, in the desaturation group indicated restrictive abnormalities, confirmed by the higher $\mathrm{FEV}_{1} / \mathrm{FVC}$ than in the normoxic group, and the similar PEF to the normoxic group. Moreover, $\mathrm{RV} / \mathrm{TLC}$ did not differ between the 2 groups, and the mean values were not higher than normal. These results imply no significant obstructive abnormalities in these subjects. Generally, interstitial lung disease shows restrictive abnormalities, including lung volume reduction and the involvement of alveolar-capillary membranes, which reduces the 6MWT distance and lowest $\mathrm{S}_{\mathrm{pO}_{2}}$ during 6MWT, due to a disturbance in gas exchange. ${ }^{15}$

The reduced percent-of-predicted $\mathrm{D}_{\mathrm{LCO}}$ in the desaturation group was most severe, at $45.8 \%$ on average, among the lung function parameters. The percent-of-predicted $\mathrm{D}_{\mathrm{LCO}} / \mathrm{V}_{\mathrm{A}}$ was also low, whereas the area under the receiver operating characteristic curve of the percent-ofpredicted $\mathrm{D}_{\mathrm{LCO}}$ was larger than that of $\mathrm{D}_{\mathrm{LCO}} / \mathrm{V}_{\mathrm{A}}$. It has been suggested that the reduced $D_{\mathrm{LCO}}$ was much greater than the loss of lung volume, because of parenchymal abnormalities. ${ }^{10}$ Moreover, low $\mathrm{D}_{\mathrm{LCO}}$ without reduced FVC is the earliest and most sensitive pulmonary functional abnormality in systemic sclerosis. ${ }^{16} \mathrm{D}_{\mathrm{LCO}} / \mathrm{V}_{\mathrm{A}}$ is also reduced in many patients, but it usually does not improve the sensitivity for detecting lung disease. The gas transfer reduction is not purely attributable to a loss of lung volume, but might also be secondary to alveolar-capillary membrane thickening and pulmonary vascular disease. In this study, since $\mathrm{D}_{\mathrm{LCO}}$ was adjusted according to the concentration of hemoglobin, it may be the preferable parameter to reflect alveolar-capillary membrane conductivity and/or pulmonary vasculopathy. ${ }^{6,17}$

The highest percent-of-predicted $\mathrm{D}_{\mathrm{LCO}}$ value in the desaturation group was $78.0 \%$ (results not shown), and the cutoff point for exercise-induced oxygen desaturation was $56.3 \%$. With that criterion, $83 \%$ of subjects were correctly predicted regarding oxygen desaturation after 6MWT, and 5 subjects were false negatives. We attempted to detect parameters to identify false negatives to reduce the risk of unexpected exercise-induced oxygen desaturation, and found that lung volume parameters and RVSP were insufficient for that purpose. There might be some other factors that affect oxygen saturation during exercise.

\section{Limitations}

We did not evaluate pulmonary arterial hypertension during and after exercise. Patients with interstitial lung disease are prone to pulmonary arterial hypertension at rest and after exercise, ${ }^{5,18,19}$ and primary pulmonary hy- pertension or exercise-induced pulmonary arterial hypertension reduce $\mathrm{S}_{\mathrm{pO}_{2}}{ }^{20}$ and percent-of-predicted $\mathrm{D}_{\mathrm{LCO}} \cdot{ }^{21}$ Those observations suggest that a high RVSP during exercise may induce oxygen desaturation. RVSP is an estimated value based on pulmonary arterial pressure measured via tissue Doppler echocardiography at rest, without catheterization, and $>40 \mathrm{~mm} \mathrm{Hg}$ was the criterion for pulmonary arterial hypertension. Although the 5 false negative subjects did not show pulmonary arterial hypertension at rest, there is a possibility that exercise-induced pulmonary arterial hypertension or other pathogenesis may have affected these subjects. Complications associated with systemic sclerosis are multiple, ${ }^{22}$ so the number and severity of affected organs differ between individual patients. Further studies of exercise-induced desaturation are required.

\section{Conclusions}

Reduced percent-of-predicted lung volumes and of $\mathrm{D}_{\mathrm{LCO}}$ affected oxygen saturation during 6MWT in patients with systemic sclerosis and interstitial lung disease. Percent-of-predicted $\mathrm{D}_{\mathrm{LCO}}$ is a good candidate for a sensitive and specific predictor of exercise-induced oxygen desaturation in such patients.

\section{REFERENCES}

1. Lama VN, Flaherty KR, Toews GB, Colby TV, Travis WD, Long Q, et al. Prognostic value of desaturation during a 6-minute walk test in idiopathic interstitial pneumonia. Am J Respir Crit Care Med 2003; 168(9):1084-1090.

2. Wallaert B, Wemeau-Stervinou L, Salleron J, Tillie-Leblond I, Perez T. Do we need exercise tests to detect gas exchange impairment in fibrotic idiopathic interstitial pneumonias? Pulm Med 2012;2012: 657180. DOI: 10.1155/2012/657180.

3. Wemeau-Stervinou L, Perez T, Murphy C, Polge AS, Wallaert B. Lung capillary blood volume and membrane diffusion in idiopathic interstitial pneumonia. Respir Med 2012;106(4):564-570.

4. Garin MC, Highland KB, Silver RM, Strange C. Limitations to the 6-minute walk test in interstitial lung disease and pulmonary hypertension in scleroderma. J Rheumatol 2009;36(2):330-336.

5. Alkotob ML, Soltani P, Sheatt MA, Katsetos MC, Rothfield N, Hager WD, et al. Reduced exercise capacity and stress-induced pulmonary hypertension in patients with scleroderma. Chest 2006;130(1): 176-181.

6. Trad S, Huong DLT, Frances C, Wechsler B, Cacoub P, Costedoat $\mathrm{N}$, et al. Impaired carbon monoxide diffusing capacity as a marker of limited systemic sclerosis. Eur J Intern Med 2011;22(6):e80-e86.

7. Villalba WO, Sampaio-Barros PD, Pereira MC, Cerqueira EMFP, Leme Jr CA, Marques-Neto JF, Paschoal IA. Six-minute walk test for the evaluation of pulmonary disease severity in scleroderma patients. Chest 2007;131(1):217-222.

8. Mugii N, Someya F, Hasegawa M. Reduced hypoxia risk in a systemic sclerosis patient with interstitial lung disease after long-term pulmonary rehabilitation. Clin Med Insights Case Rep 2011;4:53-56.

9. Wilsher M, Good N, Hopkins R, Young P, Milne D, Gibson A. et al. The six-minute walk test using forehead oximetry is reliable in the assessment of scleroderma lung disease. Respirology 2012;17(4): 647-652. 


\section{Predictors of Exercise-Induced Oxygen Desaturation in Systemic Sclerosis}

10. Pellegrino R, Viegi G, Brusasco V, Crapo RO, Burgos F, Casaburi $\mathrm{R}$, et al. Interpretative strategies for lung function tests. Eur Respir $\mathrm{J}$ 2005;26(5):948-968.

11. Meune C, Avouac J, Wahbi K, Cabanes L, Wipff J, Mouthon L. et al. Cardiac involvement in systemic sclerosis assessed by tissueDoppler echocardiography during routine care: a controlled study of 100 consecutive patients. Arthritis Rheum 2008;58(6):1803-1809.

12. Schachna L, Wigley FM, Chang B, White B, Wise RA, Gelber AC. Age and risk of pulmonary arterial hypertension in scleroderma. Chest 2003;124(6):2098-2104.

13. American Thoracic Society. Idiopathic pulmonary fibrosis: diagnosis and treatment: international consensus statement. Am J Respir Care Med 2000;161(2):646-664.

14. Hallstrand TS, Boitano LJ, Johnson WC, SPada CA, Hayes JG, Raghu G. The timed walk test as a measure of severity and survival in idiopathic pulmonary fibrosis. Eur Respir J 2005;25(1):96-103.

15. Pimenta SP, da Rocha RB, Baldi BG, Kawassaki AM, Kairalla RA, Carvalho CRR. Desaturation-distance ratio: a new concept for a functional assessment of interstitial lung diseases. Clinics 2010;65(9): 841-846.

16. Steen VD, Graham G, Conte C, Owens G, Medsger TA Jr. Isolated diffusing capacity reduction in systemic sclerosis. Arthritis Rheum 1992;35(7):765-770.
17. Dumitrescu D, Oudiz RJ, Karpouzas G, Hovanesyan A, Jayasinghe A, Hansen JE, et al. Developing pulmonary vasculopathy in systemic sclerosis, detected with non-invasive cardiopulmonary exercise testing. PLoS One 2010;5(12):e14293. DOI: 10.1371/journal. pone.0014293.

18. Koh ET, Lee P, Gladman DD, Abu-Shakra M. Pulmonary hypertension in systemic sclerosis: an analysis of 17 patients. Br J Rheumatol 1996;35(10):989-993.

19. D'Alto M, Ghio S, D'Andrea A, Pazzano AS, Argiento P, Camporotondo R, et al. Inappropriate exercise-induced increase in pulmonary artery pressure in patients with systemic sclerosis. Heart 2011; 97(2):112-117.

20. Yasunobu Y, Oudiz RJ, Sun XG, Hansen JE, Wasserman K. Endtidal Pco2 abnormality and exercise limitation in patients with primary pulmonary hypertension. Chest 2005;127(5):1637-1646.

21. Fowler RM, Jenkins SC, Maiorana AJ, Garin RK, O'Driscoll G, Gabbay E: Measurement properties of the 6-min walk test in individuals with exercise-induced pulmonary arterial hypertension. Int Med J 2011;41(9):679-678.

22. Hashimoto A, Endo H, Kondo H, Hirohata S. Clinical features of 405 Japanese patients with systemic sclerosis. Mod Rheumatol 2012; 22(2):272-279. 